\title{
Erratum to: Intravascular mucinosis: a rare cause of cerebral infarction
}

Marie Christine Bernardo $\cdot$ Jonathan Graff-Radford •

Joshua Menke - Christopher Hallemeier • Christopher J. Boes •

Mark Lewis • Bernd Scheithauer • Caterina Giannini

Published online: 6 August 2011

(C) Springer-Verlag 2011

Erratum to: Acta Neuropathol (2011) 121:785-788

DOI 10.1007/s00401-011-0829-8

Unfortunately, in the printed article, the second author's name was misspelled as Jonathan Graff Radford.

The correct name should be Jonathan Graff-Radford.

The online version of the original article can be found under doi:10.1007/s00401-011-0829-8.

M. C. Bernardo · J. Menke · B. Scheithauer · C. Giannini ( $\square)$ Department of Laboratory Medicine and Pathology,

Mayo Clinic, 200 First Street SW, Rochester, MN 55905, USA

e-mail: giannini.caterina@mayo.edu

J. Graff-Radford · C. Hallemeier · C. J. Boes · M. Lewis

Department of Neurology, Mayo Clinic, Rochester, MN, USA 